The INL is a

U.S. Department of Energy

National Laboratory

operated by

Battelle Energy Alliance

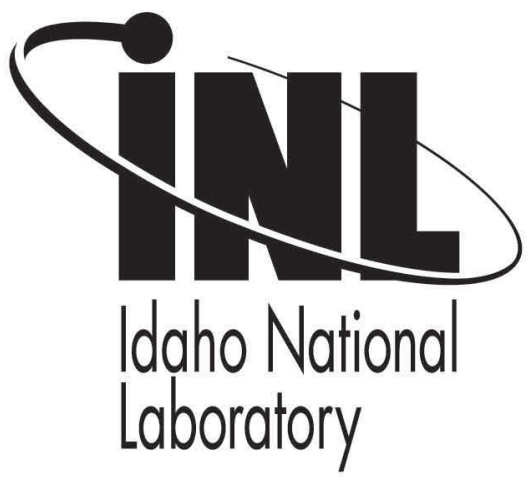

\title{
Unmanned Aerial Vehicle (UAV) Hyperspectral Remote Sensing for Dryland Vegetation Monitoring
}

\section{Hyperspectral Image and Signal Processing: Evolution in Remote Sensing}

Jessica J. Mitchell

Nancy F. Glenn

Matthew $O$. Anderson

Ryan C. Hruska

Anne Halford

Charlie Baun

Nick Nydegger

\section{June 2012}

This is a preprint of a paper intended for publication in a journal or proceedings. Since changes may be made before publication, this preprint should not be cited or reproduced without permission of the author. This document was prepared as an account of work sponsored by an agency of the United States Government. Neither the United States Government nor any agency thereof, or any of their employees, makes any warranty, expressed or implied, or assumes any legal liability or responsibility for any third party's use, or the results of such use, of any information, apparatus, product or process disclosed in this report, or represents that its use by such third party would not infringe privately owned rights. The views expressed in this paper are not necessarily those of the United States Government or the sponsoring agency. 


\title{
UNMANNED AERIAL VEHICLE (UAV) HYPERSPECTRAL REMOTE SENSING FOR DRYLAND VEGETATION MONITORING
}

\author{
Jessica J. Mitchell ${ }^{1}$, Nancy F. Glenn ${ }^{1}$, Matthew O. Anderson ${ }^{2}$, Ryan C. Hruska ${ }^{2}$, Anne Halford ${ }^{3}$ Charlie \\ Baun $^{4}$, Nick Nydegger ${ }^{4}$ \\ ${ }^{1}$ Idaho State University, Idaho USA, ${ }^{2}$ Idaho National Lab, Idaho, USA, ${ }^{3}$ Bureau of Land Management, \\ Idaho, USA, ${ }^{4}$ Idaho Military Division, Idaho, USA
}

\begin{abstract}
UAV-based hyperspectral remote sensing capabilities developed by the Idaho National Lab and Idaho State University, Boise Center Aerospace Lab, were recently tested via demonstration flights that explored the influence of altitude on geometric error, image mosaicking, and dryland vegetation classification. The test flights successfully acquired usable flightline data capable of supporting classifiable composite images. Unsupervised classification results support vegetation management objectives that rely on mapping shrub cover and distribution patterns. Overall, supervised classifications performed poorly despite spectral separability in the image-derived endmember pixels. In many cases, the supervised classifications accentuated noise or features in the mosaic that were artifacts of color balancing and "feathering" areas of flightline overlap. Future mapping efforts that leverage ground reference data, ultra-high spatial resolution photos and time series analysis should be able to effectively distinguish native grasses such as Sandberg bluegrass (Poa secunda), from invasives such as burr buttercup (Ranunculus testiculatus).
\end{abstract}

Index Terms - UAV, hyperspectral, vegetation, classification, dryland

\section{INTRODUCTION}

The development of compact imaging spectrometers deployable from small, lightweight unmanned aerial vehicles (UAVs) at low altitudes offer new opportunities in subdecimeter remote sensing. These collection systems span the gap between ground-based and coarser resolution sampling and provide on-demand, repeat assessments of complex dryland ecosystem targets, which are difficult to detect in airborne and satellite data e.g., [1], [2]. However, such low cost systems present unique challenges to geometric error correction and image mosaicking e.g., [3], [4].

Since 2009, the Idaho National Lab (INL) has developed remote sensing capabilities that combine a miniaturized hyperspectral sensor with a relatively affordable and lightweight, fixed-wing UAV. These capabilities have been routinely refined via tests flights conducted at the INL UAV runway and research park in southeastern Idaho, USA and at the Orchard Training Area (OTA) in southwestern Idaho, USA. Idaho State University (ISU) Boise Center Aerospace Lab (BCAL) has provided mission support through field data collection and image processing tasks for sensor characterization and demonstration of vegetation monitoring applications.

Most recently, UAV-based hyperspectral flights conducted at OTA on May 11, 2011, tested the extent to which increased flight altitude could reduce geometric error, improve image mosaicking, and effectively discriminate among non-vegetation targets, grasses and shrubs. This paper presents preliminary and qualitative results associated with processing and classifying imagery obtained from these demonstration flights.

\section{METHODS}

\subsection{Data collection}

A series of demonstration flights and ground reference data collections were completed across an area of land within a 4-km radius of the Range 03 runway at OTA, near Boise, Idaho, from 09 May to 12 May 2012. Data collection was conducted in cooperation with the Idaho Army National Guard and the Bureau of Land Management (BLM). The OTA is an Army National Guard joint military installation (57,996 hectares) located within the Snake River Birds of Prey National Conservation Area (NCA). The BLM is interested in prioritizing and monitoring restoration projects across the NCA within the context of ecosystem resiliency. Remote sensing monitoring components include relationships between the spatial arrangement of shrubs and disturbance gradients, vegetation cover and species composition, and native and non-native species distribution patterns.

The complete UAV-based hyperspectral collection system consists of a PIKA II imaging spectrometer and PCAQ airborne data acquisition unit (Resonon, Inc., 
Bozeman, MT); a Piccolo II autopilot (Cloud Cap Technology, Hood River, OR); and a medium altitude long endurance (over 12 hours) Arcturus T-16 airframe, which is designed to carry payloads weighing up to $8 \mathrm{~kg}$ in a 12,000 $\mathrm{cm}^{3}$ payload compartment (Arcturus UAV, Rohnert Park, CA). The PIKA II sensor is a visible/near-infrared pushbroom system configurable up to 240 bands across the $400 \mathrm{~nm}$ to $900 \mathrm{~nm}$ spectral range, with a maximum spectral resolution of $2.1 \mathrm{~nm}$.

On 11 May 2011, a full-coverage PIKA II dataset was collected over the project area at a flight altitude of $1676 \mathrm{~m}$ above ground level (AGL), which resulted in a nominal square pixel resolution of $1.1 \mathrm{~m}$ (Figure 1). The sensor was configured with 320 cross track pixels and 80 channels, with a spectral resolution of $6.3 \mathrm{~nm}$. Flightlines generated a swath width of $352 \mathrm{~m}$ and $50 \%$ side overlap was specified. In addition to the hyperspectral overflights, an ultra-high spatial resolution ( $4.2 \mathrm{~cm}$ square pixel resolution) true color digital camera was deployed from a second Arcturus T-16 airframe on 12 May 2011 to support vegetation mapping efforts.

Ground reference data were collected throughout the project area using a Trimble GeoXT (Sunnyvale, California) model GPS receiver capable of sub-meter positional accuracy. Ground control points were collected throughout the project area, as well as polygon training data for several dense, homogenous stands of sagebrush (Artemisia tridentata; ARTR), Sandberg bluegrass (Poa secunda; POSE), bur buttercup (Ranunculus testiculatus; RATE), and "slickspots". Slickspots are small, distinct ground patches characterized by a clay subsurface soil horizon and which can host the sensitive vegetation species slickspot peppergrass (Lepidium papilliferum). Ground reference data were also collected for 60 stratified random plots ( $1 \mathrm{~m} \mathrm{X} 1$ $\mathrm{m})$. The plots were stratified by shrub and non-shrub and included categorical vegetation cover information.

\subsection{Hyperspectral data processing}

Radiometric and geometric corrections were applied to individual flightlines using GeoReg post-processing geocorrection software provided by the PIKA II vendor. After post-processing was complete, the flightlines still exhibited a consistent offset of approximately $30 \mathrm{~m}$. To correct for this offset, an optimal set of biases was empirically determined in GeoReg and airframe attitude corrections (roll, pitch, heading: 3, 3.5, 1.25) were applied to the flightlines. Individual flightlines were then atmospherically corrected (Fast Line-of-sight Atmospheric Analysis of Spectral Hypercubes or FLAASH), mosaicked and classified using Environment for Visualizing Images (ENVI) version 4.8 software (ExelisVIS, Boulder, CO).
Absolute geometric error for the mosaic was assessed using 13 ground control points derived from representative locations throughout corresponding 2009 National Agriculture Imagery Program (NAIP) images (1 m pixel resolution; $\pm 3 \mathrm{~m}$ of DOQQ reference maps) and one runway control point collected from a Trimble GeoXT $( \pm 1 \mathrm{~m})$. Absolute geometric error for the mosaic was estimated at having a root mean square error (RMSE) of 7.07 meters.

\subsection{Hyperspectral image classifications}

Unsupervised and supervised classifications were applied to the hyperspectral image mosaic for the purpose of data exploration. Two commonly used unsupervised algorithms, K-Means and Isodata, were selected to examine inherent class separability. For example, we explored the extent to which grass, shrub and bare ground are spectrally distinct in the mosaic.

A number of supervised classifications were also applied to the image mosaic, including spectral angle mapper (SAM) [5] and the spectral mixture analysis method mixture-tuned matched filtering (MTMF) [6]. A SAM classification was applied to all of the hyperspectral bands and endmember spectra were derived from the mosaic for sagebrush, Sandberg bluegrass, bur buttercup, cinder, bare ground and slickspots (Figure 1). Polygon mapping of dense, homogenous targets in the field provided the basis for user-guided endmember pixel selection.

The MTMF method was applied to the hyperspectral mosaic in an attempt to delineate sagebrush cover and estimate subpixel target abundance. A minimum noise fraction (MNF) transformation [7] was applied to all of the hyperspectral bands and the first 40 bands were retained for MTMF input. Selecting the first 40 bands explained $84 \%$ of the data and avoided the introduction of noise associated with higher bands. Sagebrush endmember classification spectra were derived using two different approaches. The first approach used a spectral library of averaged field spectrometer data collected for 35 individual sagebrush canopies at a different study site in eastern Idaho [8]. The second approach used a pixel purity indexing procedure to identify potentially pure pixels in the mosaic for endmember classification. This second approach was eventually dismissed, as the majority of pixels identified by the procedure corresponded to areas of flightline overlap in the mosaic. Further, there was a lack of correspondence between clusters of spectrally pure pixels and known occurrences of sagebrush.

Supervised and unsupervised classification results were qualitatively evaluated based on shrub cover gradients in the study area and visual comparisons to 1) existing OTA vegetation maps derived from an annually constrained 


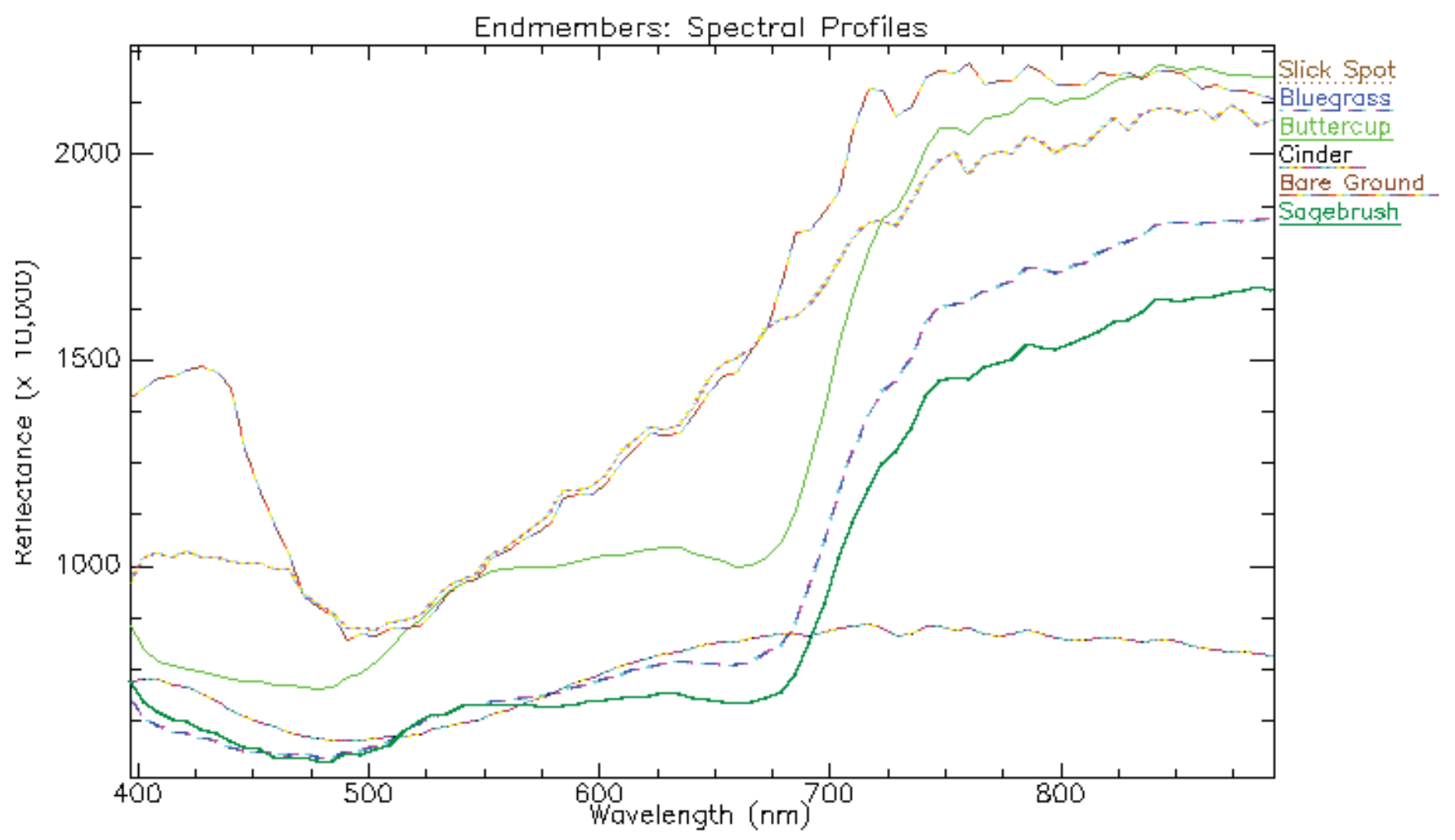

Figure 1. Plot depicting the spectral profiles of image-derived pixel endmembers. While separability between bare ground, cinder and the vegetation targets are visually obvious, it should also be pointed out that, among the vegetation spectra, buttercup has an overall brighter reflectance than sagebrush or bluegrass. All three vegetation targets have reflectance peaks in the green $(\sim 550 \mathrm{~nm})$ and red $(\sim 625 \mathrm{~nm})$ portions of the visible spectrum. The magnitude of green reflectance is the same for both sagebrush and bluegrass. However, sagebrush can be distinguished from bluegrass by the higher reflectance in the red and brighter reflectance along the red edge $(\sim 725 \mathrm{~nm})$ in the bluegrass spectrum.

temporal analysis of Landsat imagery (2000, Nydegger, Environmental Management Office, State of Idaho Military Division) and 2) the ultra-high spatial resolution digital photos that were acquired over the study area during the hyperspectral data collection, and 3) general cover information associated with the 60 sample plots.

\section{RESULTS}

Preliminary evaluation of the mosaicked imagery indicates that increasing flight overlap and altitude and coarsening the pixel resolution addresses several issues related to high frequency noise, geo-locational error and incomplete coverage (Figure 2).

\subsection{Unsupervised classifications}

While the K-means unsupervised classification method produced results visually inconsistent with known distribution patterns in the project area, an IsoData classification method ( 5 classes; minimum class distance of 10 units) produced comparatively similar results to the current OTA vegetation map (Figure 3). The general sagebrush distribution pattern was consistent between maps, although the mosaic contained a great deal of detail due to the high pixel resolution $(1.1 \mathrm{~m} \mathrm{X} 1.1 \mathrm{~m})$. Given the known association between shrubs and shadow, areas in the hyperspectral classification (Figure 3a) that contained shrub with a high degree of shadow mixing appeared to correspond to areas in the current OTA vegetation map (Figure 3b) classified as rabbitbrush.

Evaluations of the IsoData classification method using several of the ultra-high spatial resolution aerial photographs also suggested reasonable results. For example, areas containing complex distributions of bare ground patches surrounded by grass/forb were validated using the ultra-high resolution aerial photographs (e.g, Figure 4). Differences between the two sets of imagery were attributed to scale: as 


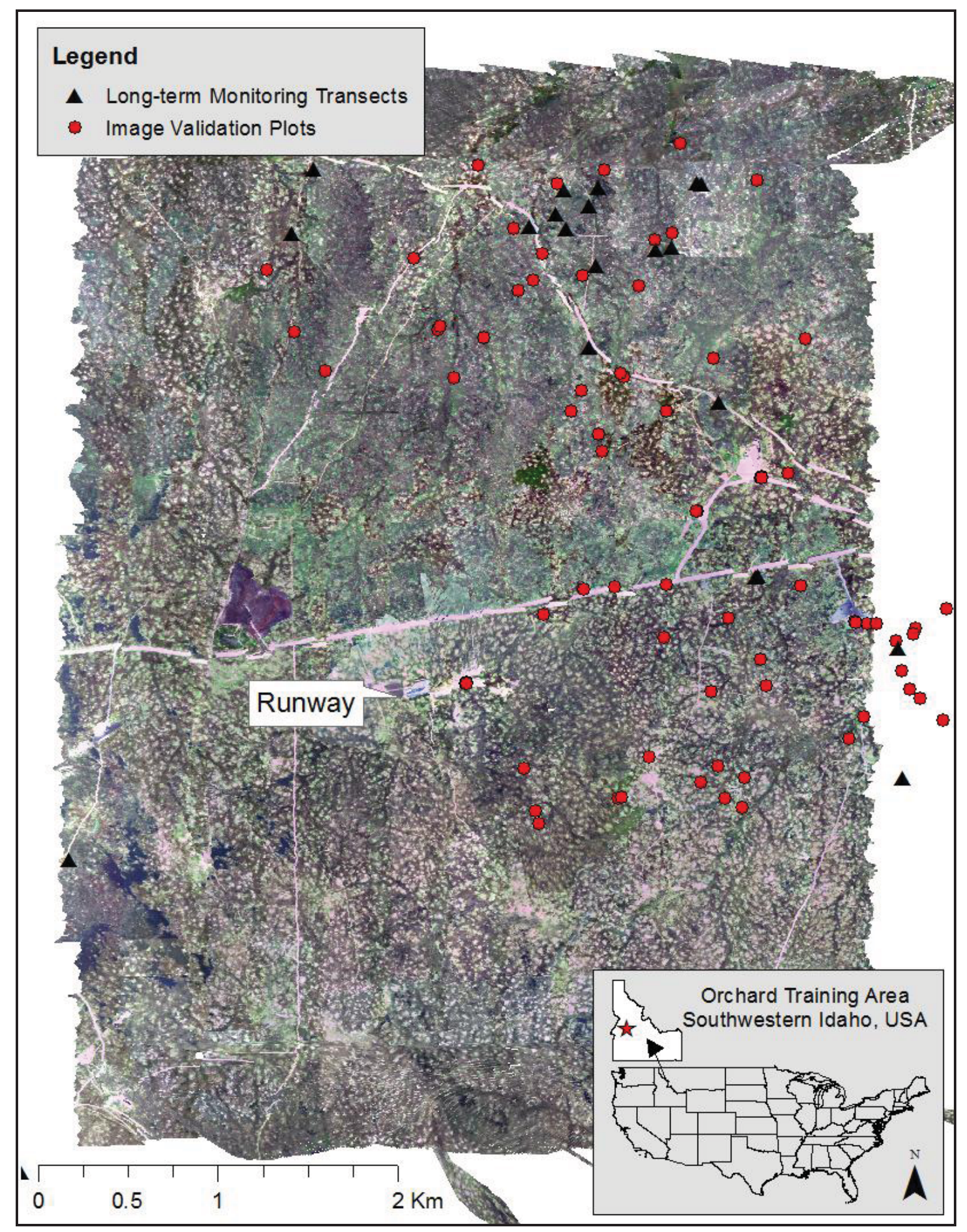

Figure 2. 2011 Hyperspectral coverage (PIKA II) collected in the vicinity of OTA Range 3 Runway. Imagery were obtained from an Arcturus T-16 airframe flying at an elevation of approximately $1676 \mathrm{~m}$ above ground level, with a nominal pixel resolution of $1.1 \mathrm{~m} \mathrm{X} 1.1 \mathrm{~m}$. 

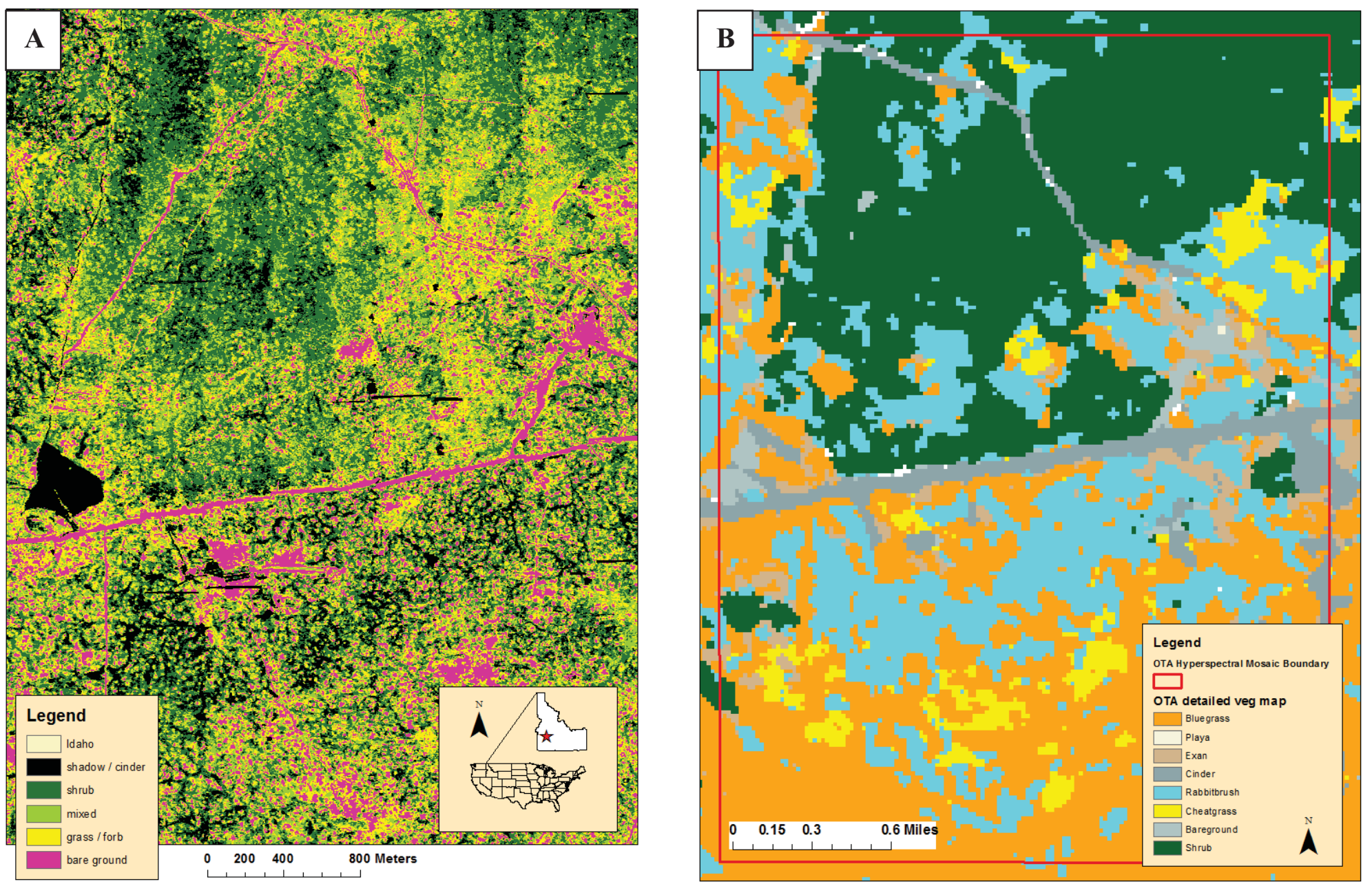

Figure 3: An unsupervised classification (a) was generated from the hyperspectral mosaic, and results were visually compared to a detailed OTA vegetation map (b) derived from year 2000 multi-temporal Landsat images (Nydegger, Environmental Management Office, State of Idaho Military Division). The general sagebrush distribution pattern is consistent between maps, although the mosaic contains a great deal of detail due to the high pixel resolution $(1.1 \mathrm{~m}$ X $1.1 \mathrm{~m})$. 


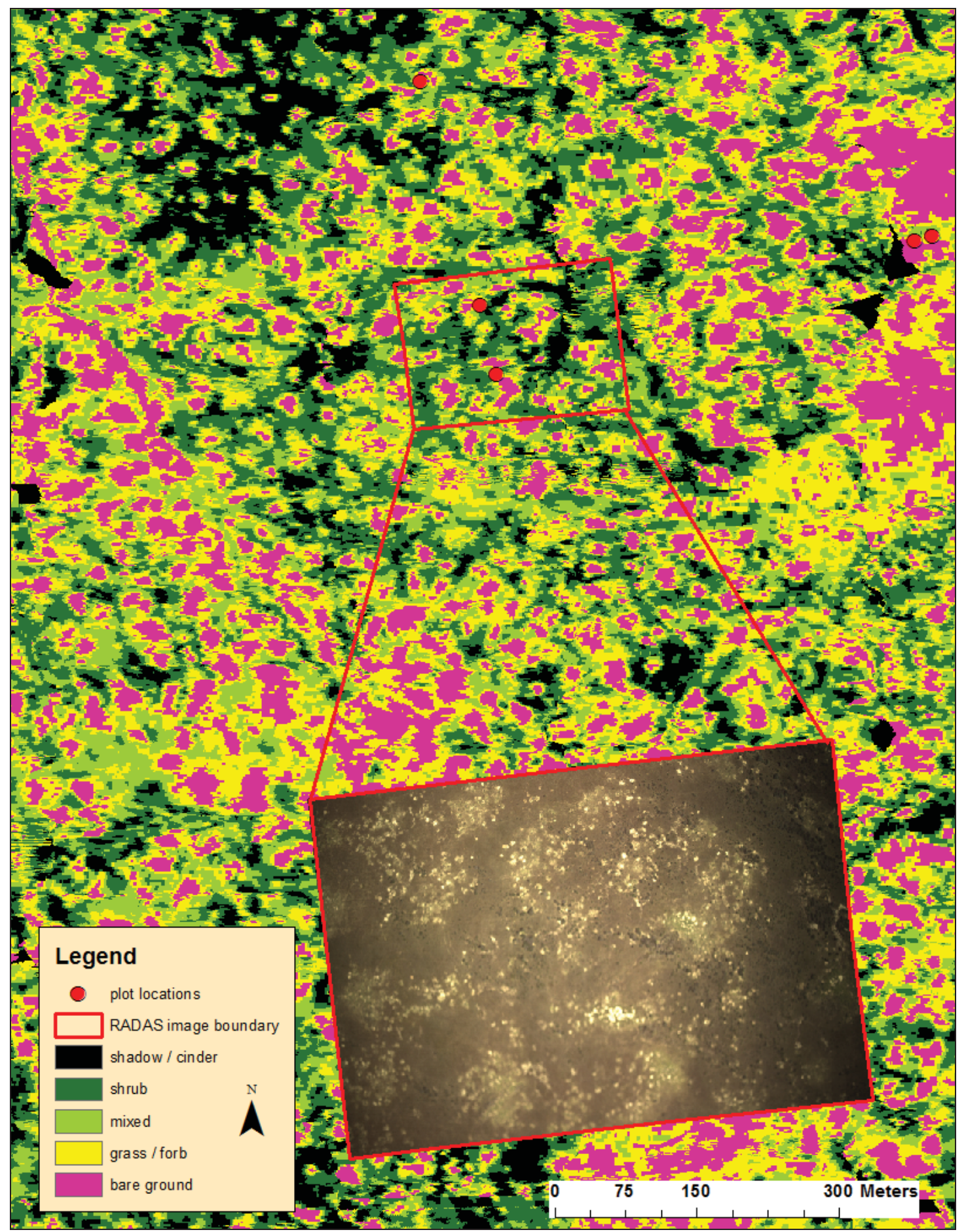

Figure 4. Here the IsoData unsupervised classification method is evaluated for the southeastern portion of the OTA hyperspectral mosaic using an ultrahigh spatial resolution $(4.2 \mathrm{~cm}$ pixels) image (RADAS) as a basis for comparison. The complex distribution of bare ground patches (magenta) surrounded by grass/forb (light green) is valid based on the ultra-high spatial resolution digital image. 
spectral information is averaged across a coarser pixel resolution $(1.1 \mathrm{~m})$ in the hyperspectral mosaic, some signals associated with grass / forb are masked by the brightness of bare ground reflectance and classified as bare ground. The bare ground issue is well documented for semi- arid landscapes e.g., [9] and this classification behavior is expected in portions of the project area where vegetation cover is sparse.

Despite some confusion between grass and bare ground in portions of the project area where cover is sparse, the extent of three isolated slickspot occurrences, located in an area of healthy sagebrush, appear to be mapped correctly (Figure 5). Although it is difficult to spectrally distinguish slickspots from other bare ground features such as dirt roads and rocky bare ground, a screening method based on texture and association could be developed to detect potential slickspot occurrences by examining small, isolated patches that are classified as bare ground.

Additional comparisons indicated that there is a spectral distinction in the hyperspectral classification between areas of relatively dense sagebrush cover and areas where shrub cover is lower and the grass / forb understory is more visible to the sensor (Figure 6).

\subsection{Supervised classifications}

The plot of spectral profiles for the image-derived endmember training pixels suggests separability between bare ground, cinder, sagebrush, burr buttercup, and Sandberg bluegrass in the $400-900 \mathrm{~nm}$ range (Figure 1). While separability between bare ground, cinder and the vegetation targets are visually obvious, it should also be pointed out that, among the vegetation spectra, burr buttercup has an overall brighter reflectance than sagebrush or bluegrass. All three targets have reflectance peaks in the green $(\sim 550 \mathrm{~nm})$ and red $(\sim 625 \mathrm{~nm})$ portions of the visible spectrum. The magnitude of green reflectance is the same for both sagebrush and bluegrass. However, sagebrush can be distinguished from bluegrass by a higher reflectance in the red and brighter reflectance along the red edge $(\sim 725$ $\mathrm{nm}$ ) of the bluegrass spectrum.

A series of supervised classifications were applied to the hyperspectral mosaic and results were extensively analyzed. All attempts to estimate subpixel target abundance for sagebrush, cinder, bare ground, grass/forb and shadow using an MTMF classification were unsuccessful. Experimentation with sagebrush endmembers derived from a variety of sources (e.g., user-driven, field spectrometer reflectance measurements, ENVI target detection wizard) did not yield a viable map of sagebrush cover. Several other supervised classification methods that were evaluated produced similarly poor results (i.e., including Spectral
Angle Mapper (SAM), Constrained Energy Minimization, Orthogonal Subspace Projection and support Vector Machine). The supervised classifications generated results that were not only inconsistent with known sagebrush distribution gradients in the project area, but tended to emphasize either areas of flight overlap and pixel distortion, or areas associated with relatively high reflectance, such as burrows, mounds and bare ground.

\section{DISCUSSION AND CONCLUSIONS}

UAV-based hyperspectral test flights at the OTA successfully acquired usable flightline data capable of supporting classifiable composite images. Preliminary results of the unsupervised classification support management objectives that rely on mapping shrub cover and distribution patterns.

Overall, supervised classifications performed poorly despite spectral separability in the image-derived endmember pixels. The MTMF subpixel unmixing algorithm failed to leverage the high spectral dimensionality of the data to estimate sagebrush cover, even though the unsupervised IsoData classification demonstrated spectral distinction between areas of high and low shrub cover. In many cases, the supervised classifications accentuated noise or features in the mosaic that were artifacts of color balancing and "feathering" areas of flightline overlap. Future supervised classification efforts should focus on endmember derivation and mosaicking procedures and consider a single flightline analysis approach in which the spectral integrity of the data are preserved.

Quantitative accuracy assessments were unattainable for this study due to lens aperture complications that limited the use of ultra-high spatial resolution photos. The 60 categorical cover plots $(1 \mathrm{~m} \mathrm{X} 1 \mathrm{~m})$ were also of limited use due to the geometric accuracy of the hyperspectral mosaic ( $7.07 \mathrm{~m}$ ) and lack of a direct method to estimating sagebrush cover (i.e. poor MTMF performance and faulty ultra-high spatial resolution imagery). It is likely that the collection of additional ground reference data, including extensive training polygons, would improve classification performance. Future mapping efforts that leverage ground reference data, ultra-high spatial resolution photos and time series analysis should be able to effectively distinguish native grasses, invasives and shrubs using the higher reflectance spectrum of the burr buttercup and the higher peak in the red and along the red edge of the bluegrass.

\section{REFERENCES}

[1] P.J. Hardin, and M. W. Jackson, "An unmanned aerial vehicle for rangeland photography," Rangeland Ecology and Management, Allen Press, Kansas, USA, pp. 439-442, July 2005. 


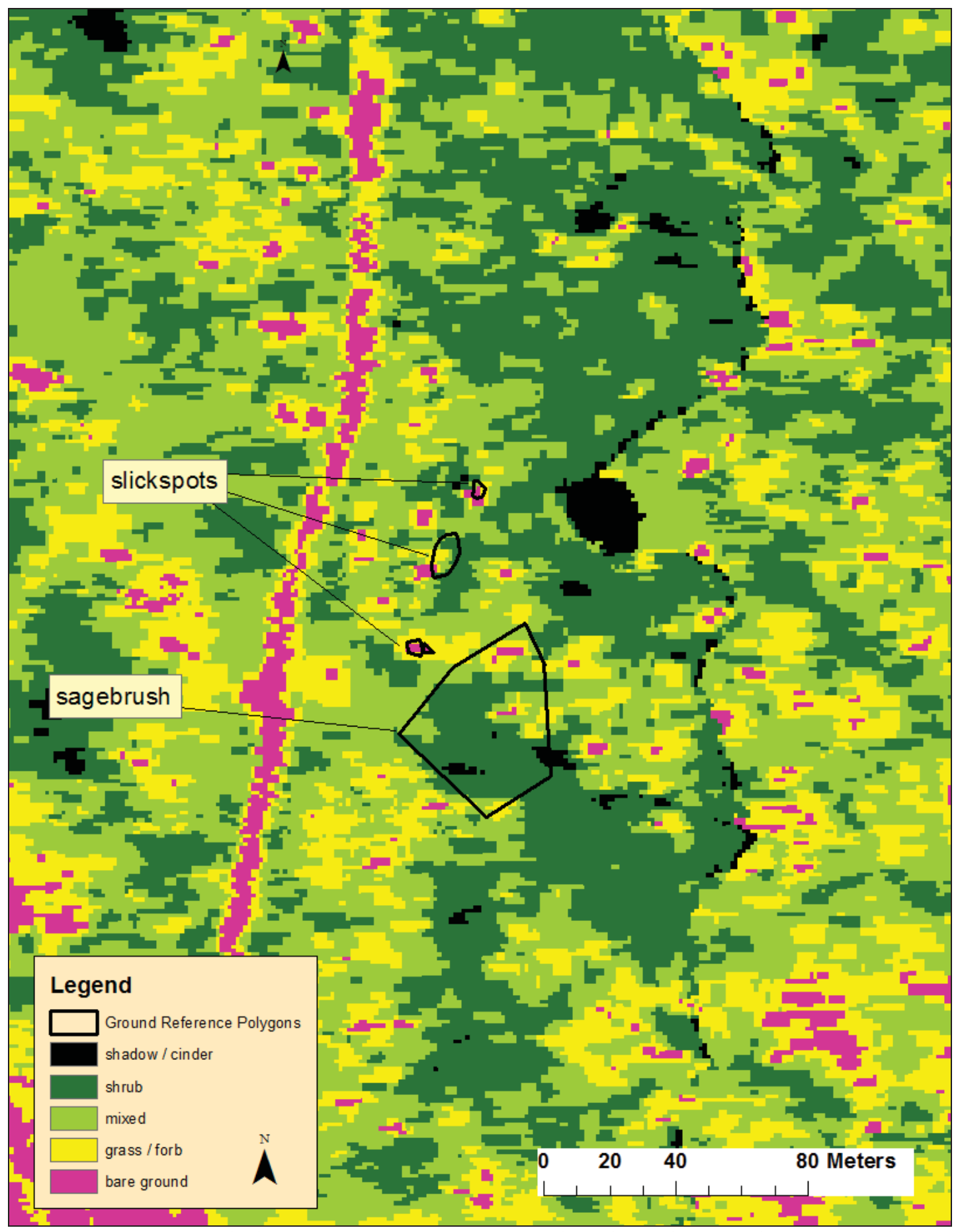

Figure 5. Unsupervised classification performance is evaluated for the central portion of the OTA hyperspectral mosaic using ground reference polygons of slickspot and sagebrush as a basis for comparison. . Despite some confusion between grass and bare ground in portions of the project area where cover is sparse, the extent of three isolated slickspot occurrences, located in an area of healthy sagebrush, appear mapped correctly 


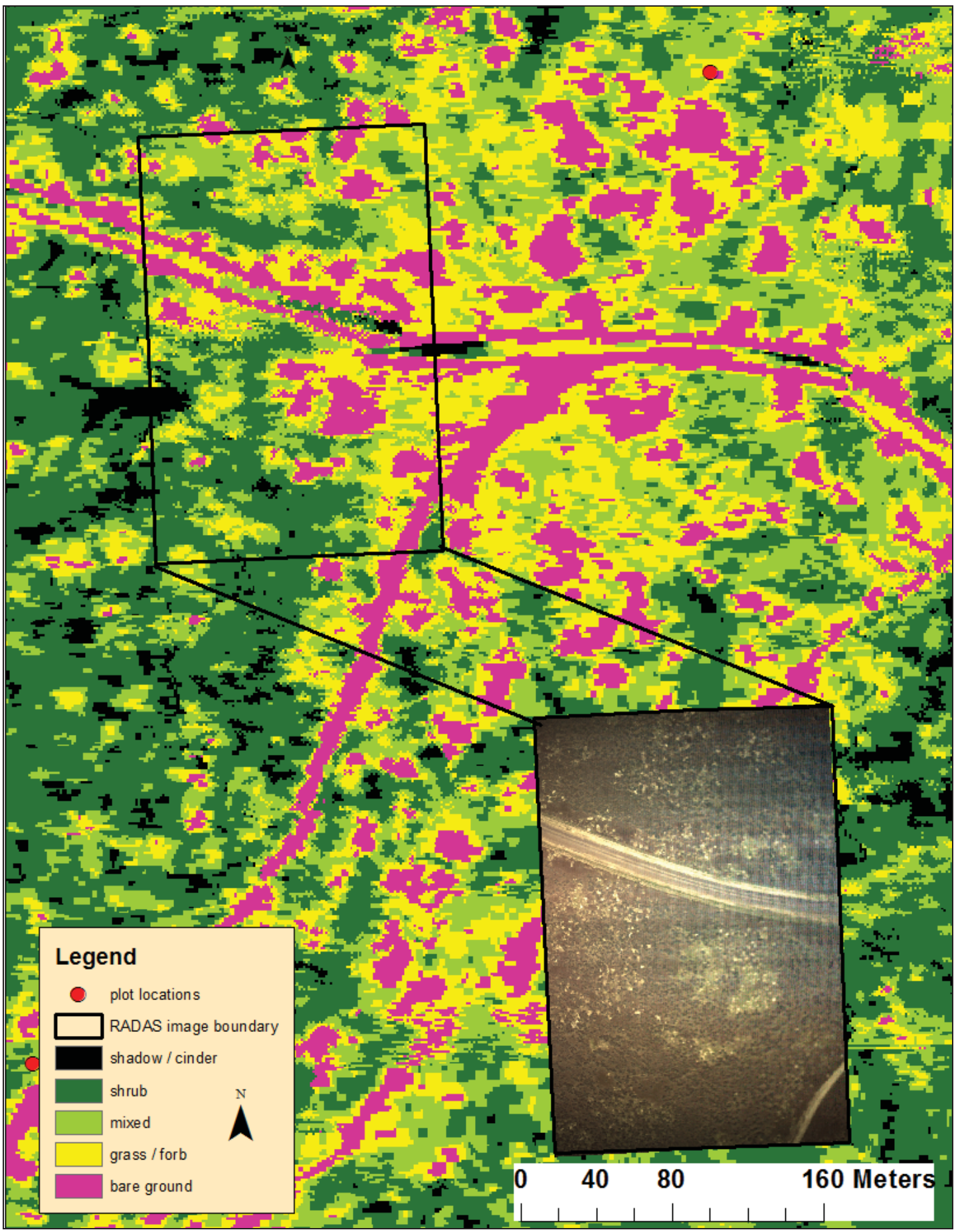

Figure 6: Here the IsoData unsupervised classification method is evaluated for the north-central portion of the OTA hyperspectral mosaic using another RADAS image as the basis for comparison. Mapping results indicate that there is a spectral distinction between areas of relatively dense sagebrush cover (dark green) and areas where shrub cover is lower and the grass / forb understory is more visible to the sensor (light green). 
[2] A. S. Laliberte and A. Rango, "Texture and scale in objectbased analysis of subdecimeter resolution unmanned aerial vehicle (UAV) imagery," IEEE Transactions on Geoscience and Remote Sensing, New Jersey, USA, pp.761-770, March 2009.

[3] H. Chao, M. Baumann, A. Jensen, Y. Chen, Y. Cao, W. Ren and M. McKee, "Band-reconfigurable mutli-UAV-based cooperative remote sensing for real-time water management and distributed irrigation control," Proceedings of the $17^{\text {th }}$ International Federation of Automatic Control, Elsevier Science Inc., USA, 2008.

[4] R. Hruska, J. Mitchell, M. Anderson, and N. Glenn, “Analysis of Hyperspectral Imagery Acquired from Tier II Class Unmanned Aerial Vehicles (UAV)," IEEE Transactions on Geoscience and Remote Sensing, in review.

[5] Kruse, F., A. Lefkoff, J. Boardman, K. Heidebrecht, A. Shapiro, P. Barloon and A. Goetz, "The spectral image processing system (SIPS)-interactive visualization and analysis of imaging spectrometer data," Remote Sensing of Environment, Elsevier Science Inc., USA, pp. 145-163, May-June 1993.
[6] Boardman, J. W., "Leveraging the high dimensionality of AVIRIS data for improved sub-pixel target unmixing and rejection of false positives: mixture tuned matched filtering," Summaries of the Seventh JPL Airborne Earth Science Workshop, NASA Jet Propulsion Laboratory, Pasadena, CA, USA, pp. 55-56, 1998.

[7] Green, A. A., Berman, M., Switzer, P. and Craig, M. D., “A transformation for ordering multispectral data in terms of image quality with implications for noise removal," IEEE Transactions on Geoscience and Remote Sensing, New Jersey, USA, pp. 65-74, January 1988.

[8] Mitchell, J., Glenn, N., Sankey, T., Derryberry, D., Anderson, M. and Hruska, R. 2012. Spectroscopic detection of Nitrogen concentrations in sagebrush: implications for hyperspectral remote sensing, Remote Sensing Letters, 3 (4), 285-294.

[9] G. S. Okin, D. A. Roberts, B.Murray, and W. J. Okin, Practical limits on hyperspectral vegetation discrimination in arid and semiarid environments," Remote Sensing of Environment, Elsevier Science Inc., USA, pp. 212-215, 2001. 